This item was submitted to Loughborough's Research Repository by the author.

Items in Figshare are protected by copyright, with all rights reserved, unless otherwise indicated.

\title{
Quantifying the variability of wind energy
}

PLEASE CITE THE PUBLISHED VERSION

http://dx.doi.org/10.1002/wene.95

PUBLISHER

(c) Wiley Periodicals Inc.

VERSION

SMUR (Submitted Manuscript Under Review)

LICENCE

CC BY-NC-ND 4.0

REPOSITORY RECORD

Watson, Simon J.. 2019. "Quantifying the Variability of Wind Energy". figshare.

https://hdl.handle.net/2134/17941. 
This is the pre-peer reviewed version of the following article: Watson S J (2013).

'Quantifying the Variability of Wind Energy', Wiley Interdisciplinary Reviews: Energy

and Environment (2013) Early View, which has been published in final form at

http://onlinelibrary.wiley.com/doi/10.1002/wene.95/abstract

\section{Article title: Quantifying the variability of wind energy}

\section{Simon Watson}

\section{First author:}

Simon Watson, Professor of Wind Energy, Centre for Renewable Energy Systems

Technology, School of Electronic, Electrical and Systems Engineering, Loughborough

University, LE67 5AH, UK, s.j.watson@lboro.ac.uk

\section{Abstract}

Wind by its very nature is a variable element. Its variation is different on different timescales and spatially its magnitude can change dramatically depending on local climatology and terrain. This has implications in a variety of sectors, not least the wind energy sector. The accuracy of weather forecasting models has increased significantly in the last few decades and these models are able to give an insight into variability on the hourly and daily timescales. On shorter timescales, predicting chaotic turbulent fluctuations is far more challenging. Similarly, the ability to make seasonal forecasts is extremely limited. General Circulation Models (GCMs) can give insights into possible future decadal fluctuations but there are still large uncertainties. Observational data can give useful information concerning variation on a variety of timescales but data quality and spatial coverage can be variable. An understanding of local scale spatial variations in wind is extremely important in wind farm siting. In the last 40 years, there have been significant advances in predicting these variations using computer models, though there remain significant challenges in understanding the behaviour of the wind in certain environments. Both the spatial and temporal variations of wind are important considerations when wind power is integrated into electricity networks and this will become an ever more important consideration as wind generation makes an increasing contribution to our global energy needs.

Keywords: wind power, variability, trends, climate change, integration, networks

\section{The Importance of Wind Variability}

Understanding how wind varies on both the temporal and spatial scales is important in many branches of the physical sciences and in engineering. Wind power is still a rapidly growing source of electricity generation despite global economic uncertainties ${ }^{1}$ and understanding how it varies on these scales is extremely important for the energy industry. The advent of ever more powerful computers has allowed predictions of wind speeds in areas where measurements are sparse and has also provided an opportunity to try and predict future trends. 
On a temporal scale, understanding the variation of wind speeds is important for:

- turbine design and siting on the very shortest timescales: $1 \mathrm{~s}$;

- operation of a power network on intermediate timescales : $\sim 1 \mathrm{~h}$ to a few days;

- energy yield on longer timescales : months to years.

An overview will be given of our present understanding of these latter two using a variety of data sources and analysis methods.

Understanding the distribution of wind speeds at a site is important in terms of estimating the capacity factor and energy yield of a wind turbine and a review of this will be given to show how well the commonly used theoretical distributions fit observations. Longer term temporal and spatial variability will be addressed looking at research using observed surface data, proxy data such as pressure fields and model data. Looking to the future, an overview of climate change related predictions of wind speeds will be given for different regions.

Finally, an overview will be given of the research to address the impact of wind variability on wind power generation. This will consider how geographical dispersion and wide area interconnection could help reduce overall variability and help the long term integration of wind energy into power systems.

\section{An Overview of Different Scales of Variability}

Much of our understanding of the temporal variability of wind stems from work done by Van der Hoven $^{2}$, despite shortcomings in the collection and analysis of the data underpinning this work. Figure 1 shows the power spectral density determined from wind speed data collected at the Brookhaven National Laboratory in the USA which was the basis of Van der Hoven's work and which has been widely referenced since. It can be seen that the spectrum apparently show three obvious peaks: one at around four days corresponding to the passage of weather systems; one at 12 hours reflecting a harmonic of the diurnal cycle; and one around one minute corresponding to turbulence. The reason for the lack of a 24 hour peak is unclear and was put down to the measurements being made at around $100 \mathrm{~m}$, though this does not explain why there was a 12 hour peak. Between the 12 hour peak and the turbulence peak, the magnitude of the spectrum drops to almost zero and this has become known as the 'mesoscale' or 'spectral gap' and is often used as a justification for averaging wind speeds, for the purposes of climatological assessment, over 10 minute or one hour intervals. However, the spectrum was derived from data collected from more than one height over different periods and in particular, the turbulent peak was determined purposely from data collected over a day when a hurricane passed over the site. This was presumably to highlight the turbulence peak as shown in Figure 1. Figure 2 shows a similar power spectral derived for oneminute and five-second data collected from the Rutherford Appleton Laboratory (STFC-RAL) site over a number of years (Barton; private commincation). In contrast to the Van der Hoven spectrum, the turbulence peak is far less marked and though there is evidence for a spectral gap there is still significant power in the spectrum at around one hour. There has since been much debate since about the existence or otherwise of a spectral gap $\mathrm{p}^{3-5}$ which, at the very least, suggests that it may well be site dependent. A strong diurnal cycle of wind speeds can be seen with a definite harmonic at 12 hours and evidence of a higher order harmonics at six hours (due to an imperfect sinusoidal variation in daily wind speeds). There is a broad peak centred around four days though this would 
seem to be broader than in the case of the Van der Hoven spectrum. An annual cycle is obvious and there is evidence for some power in the spectrum at even longer timescales. Indeed, the longer term variability of wind speeds has been the subject of interest in recent years, particularly within the wind energy industry as developers and operators of wind farms try to determine expected long term energy yields, something which is of paramount importance for the financing of a particular installation. The evidence of variance at longer time scales is discussed below. It may be that variance on timescales longer than 50 years exists, but the data to infer this are scarce. The best that can be said is that variance can be expected at all scales and that this leads to a degree of uncertainty in estimation of mean and turbulent quantities.

A number of authors have commented on the lack of stationarity in wind speeds at various timescales ${ }^{5-7}$, and this presents a particular challenge when attempting to parameterise quantities such as mean wind speeds, turbulent time and length scales, etc. Figure 1 and Figure 2 lend support to this hypothesis where it is seen that there is variance over a large range of timescales. What these figures cannot show is the degree of non-linear interaction between the different scales of variation which surely exist. The separation of different scales of variability represents a significant challenge in many areas of wind engineering.

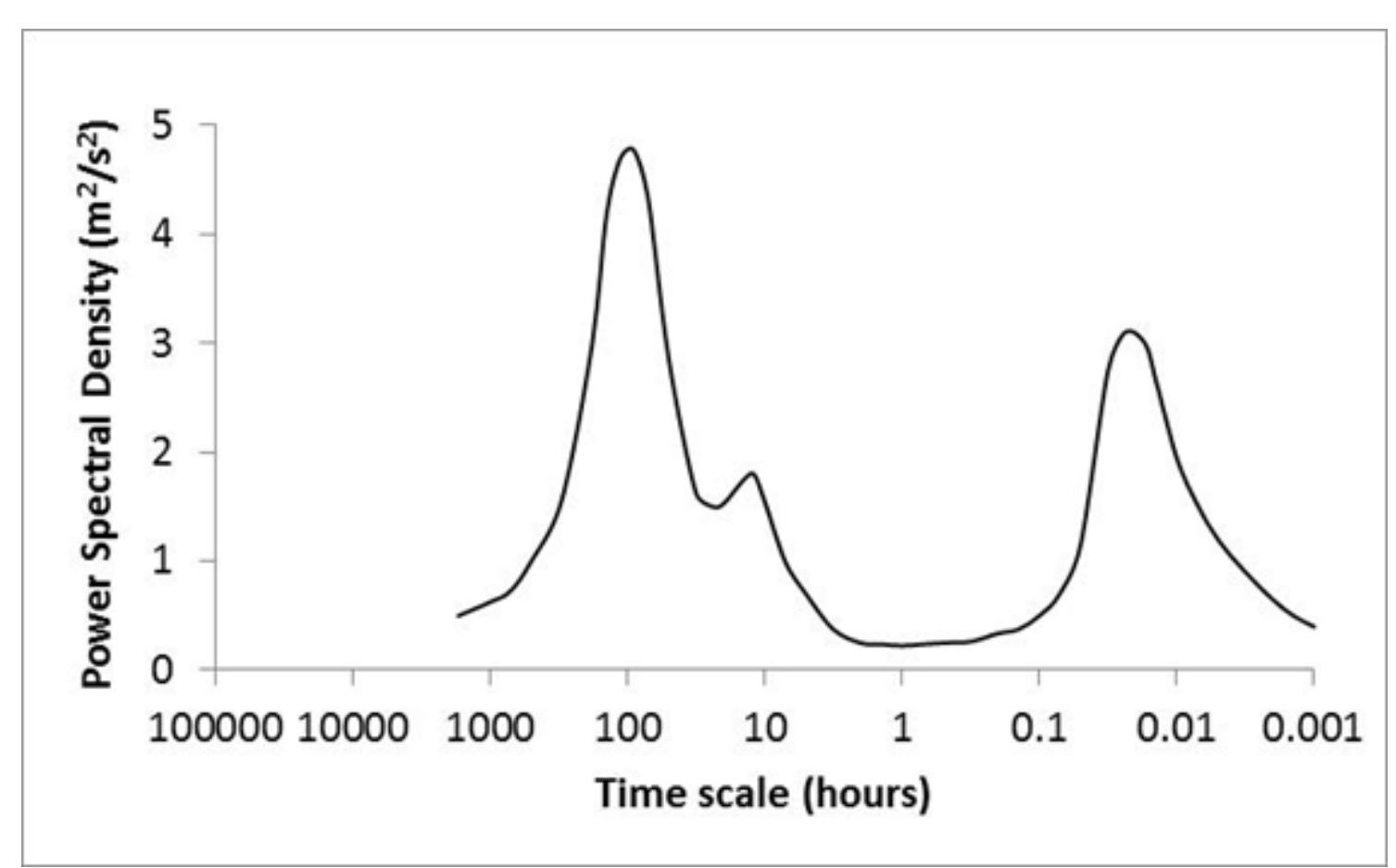

Figure 1: The Van der Hoven spectrum of wind speeds at Brookhaven National Laboratory, USA. 


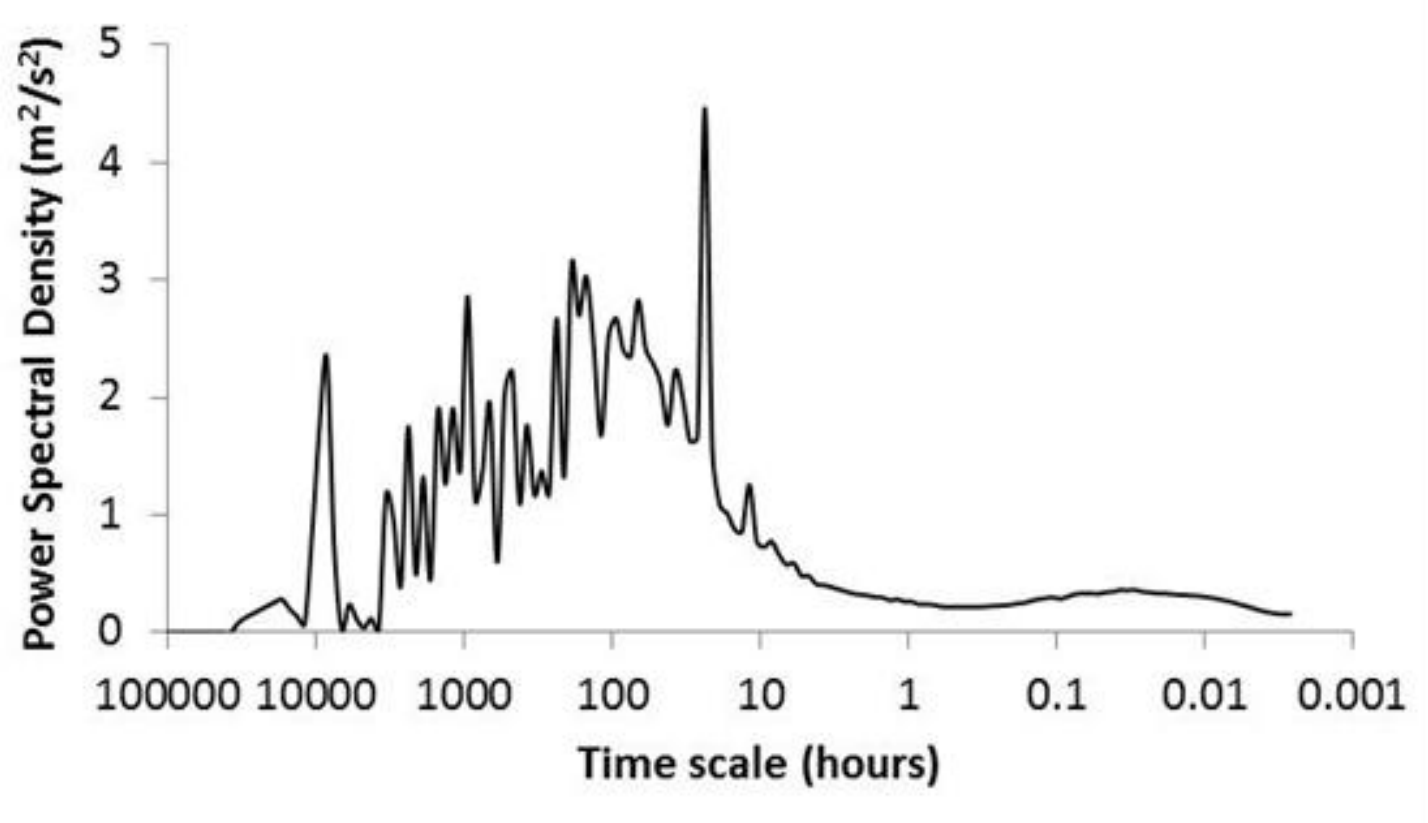

Figure 2: Power spectrum density of wind speeds based on data collected at STFC-RAL, UK.

\section{Wind Speed Distributions}

The distribution of wind speeds at a site is important in terms of the expected capacity factor of a wind turbine. Commonly used is the so-called Weibull distribution ${ }^{8}$, where the two-parameter form of the probability density function $f$ is given by:

$$
f(u)=k \frac{u^{k-1}}{C^{k}} \exp \left(-\left(\frac{u}{C}\right)^{k}\right)
$$

when observing a wind speed $u$ with Weibull scale, $C$ and shape, $k$ parameters. This has been shown to fit well at many sites ${ }^{9,10}$ and can be used to provide an accurate estimate of wind energy production ${ }^{11}$. However, discrepancies have been noted, e.g. in the US where this distribution fits wind speeds well during the day, but at night, wind speeds are observed to be more positively skewed $^{12,13}$. From scatterometer data, offshore wind speeds have been shown to be almost Weibull distributed, but the skewness of the observed distribution was found to be more strongly negative in the Tropics, and more strongly positive in northern hemisphere mid-latitudes, than would be expected for a true Weibull distribution ${ }^{14}$. This behaviour was found to be consistent for all seasons ${ }^{15}$. Scatterometer data from extra-tropical latitudes were seen to not follow a Weibull distribution though this was partly attributed to data cut-off below $2 \mathrm{~m} / \mathrm{s}^{16}$. Scatterometer data off the coast of Japan were compared with buoy data showing good agreement with these data and were well-fitted by a Weibull distribution ${ }^{17}$. A study of scatterometer-derived wind speeds in the North and Baltic Seas ${ }^{18}$, showed a relatively small bias in mean wind speed compared with observations, though problems in the interpretation and processing of scatterometer data are acknowledged due to the effects of rain, atmospheric stability, varying sea surface temperature, 
oceanic currents and proximity to land. On the other hand, wind speed data from sites in the North Sea measured on platforms have been shown to be well fitted by a Weibull distribution ${ }^{19}$.

Where wind speed distributions are bi-modal, or where a large number of calms or low wind speeds are observed $^{20}$, a single Weibull distribution may not be appropriate ${ }^{21}$, though poor quality anemometry at low speeds may be partly responsible ${ }^{22}$. In such cases, a combination of two Weibull distributions has been found to provide a better $\mathrm{fit}^{21-24}$. An example of three different functions fitted to an observed distribution of wind speeds is shown in Figure $3^{25}$. It can be seen that the combination of the two Weibull probability density functions is able to capture the bi-modal nature of this wind speed distribution with the Singly Truncated from below Normal Weibull (TNW) probability density function better capturing the large number of calms.

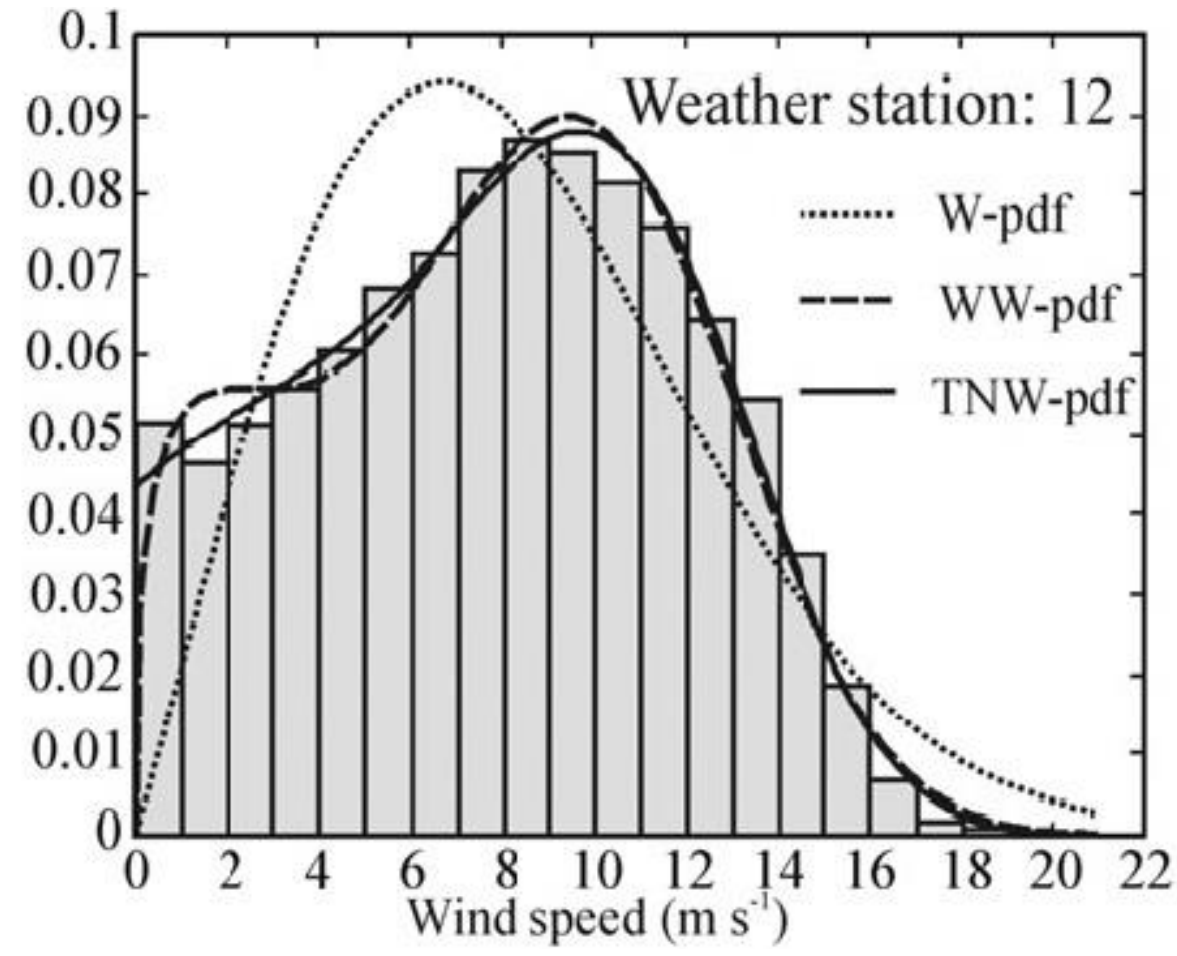

Figure 3: Histogram of observed wind speeds with three theoretical distributions fitted. $W=W e i b u l l ; ~ W W=b i-$ modal Weibull; TNW=Singly Truncated from below Normal Weibull. Reprinted from Ref. 25 with permission from Elsevier.

\section{Long Term Trends}

\section{A View from Observations}

The most obvious way to assess long term variability of wind speeds is to examine historic long term records of observed surface station observations. A map summarising the results of 148 studies $^{26}$ is shown in Figure 4. What is striking is the overall trend of reducing wind speeds. When the authors averaged all studies, this led to an average global change in wind speeds of $-0.014 \mathrm{~m} / \mathrm{s}$ per year. In a similar study ${ }^{27}$, a trend of declining world-wide wind speeds was seen, though it was noted that the statistical relevance of some the trends was hard to assess. Another study of global long term wind speeds suggested that over the Northern hemisphere, wind speeds have declined $-0.011 \mathrm{~m} / \mathrm{s}$ per 
year over a period of 30 years ${ }^{28}$. There may be a number of reasons for this, but another significant observation, also noted in Ref 5 , is an apparent trend to increasing wind speeds at exposed coastal sites. This leads to a possible explanation of increasing surface roughness on land due to vegetation cover or due to urbanisation.

No data are shown for the UK, but two recent studies have been made of wind speeds in this region. Based on $\sim 50$ years of data ${ }^{29}$, it was observed that winds over the UK as a whole did not seem to show a significant change once historic changes to measurement height were taken into consideration, however, there was a tentative tendency to reducing wind speeds in the north-west of the UK and increasing in the south-east. Over the central belt of Scotland, there was evidence for reducing wind speeds over a $\sim 40$ year period ${ }^{30}$.

It is clear from the above studies that it is difficult to distinguish wind speed changes which are climatologically driven from those resulting from other site specific factors. The use of surface wind speed observations is problematic where the quality of the data is unknown, with regard to such factors as anemometer type and calibration, siting, exposure, measurement height, etc. It is also difficult to draw definitive conclusions from datasets covering different time periods and where observations are sparse.

Some researchers have turned to the use of pressure measurements to try and overcome this problem $^{31-33}$. For example, pressure triangles based on site measurements of atmospheric pressure were used to infer a pressure gradient and thus the geostrophic wind ${ }^{33}$ for the period 1984-2007 for the north-eastern Atlantic region. In a similar, much earlier study ${ }^{34}$, a gridded dataset of pressure measurements was used to derive pressure gradients and a set of linear regression equations developed to predict long term monthly wind speed records at a number of UK sites for the period 1881-1989. The North-Atlantic Oscillation (NAO) index has long been known to correlate to observed wind speeds in northern Europe, particularly during the winter. This index is traditionally based on the pressure difference between a site in Iceland and the Azores. Using this index, it has been shown ${ }^{35}$ that there is up to a $10 \%$ difference in wind power predicted output between high and low NAO states, implying a significant degree of inter-annual variability.

Several proxies for surface wind speed have been studied including the NAO, the Grosswetterlagen and Jenkinson Lamb indices ${ }^{36}$, the latter two being popular weather system classification schemes. These showed a reasonable degree of agreement $\left(R^{2}=0.49\right)$ and suggested a downward trend in windiness across north-western Europe in the fifteen year period 1990-2005 though there was an upward 'blip' during the 1990s. It could also be seen that over the longer term (1965-2005) this downward trend was not apparent. The conclusion from this work was that care should be taken when choosing an appropriate historic period to assess the expected long term wind speed climate at a prospective wind farm site. 


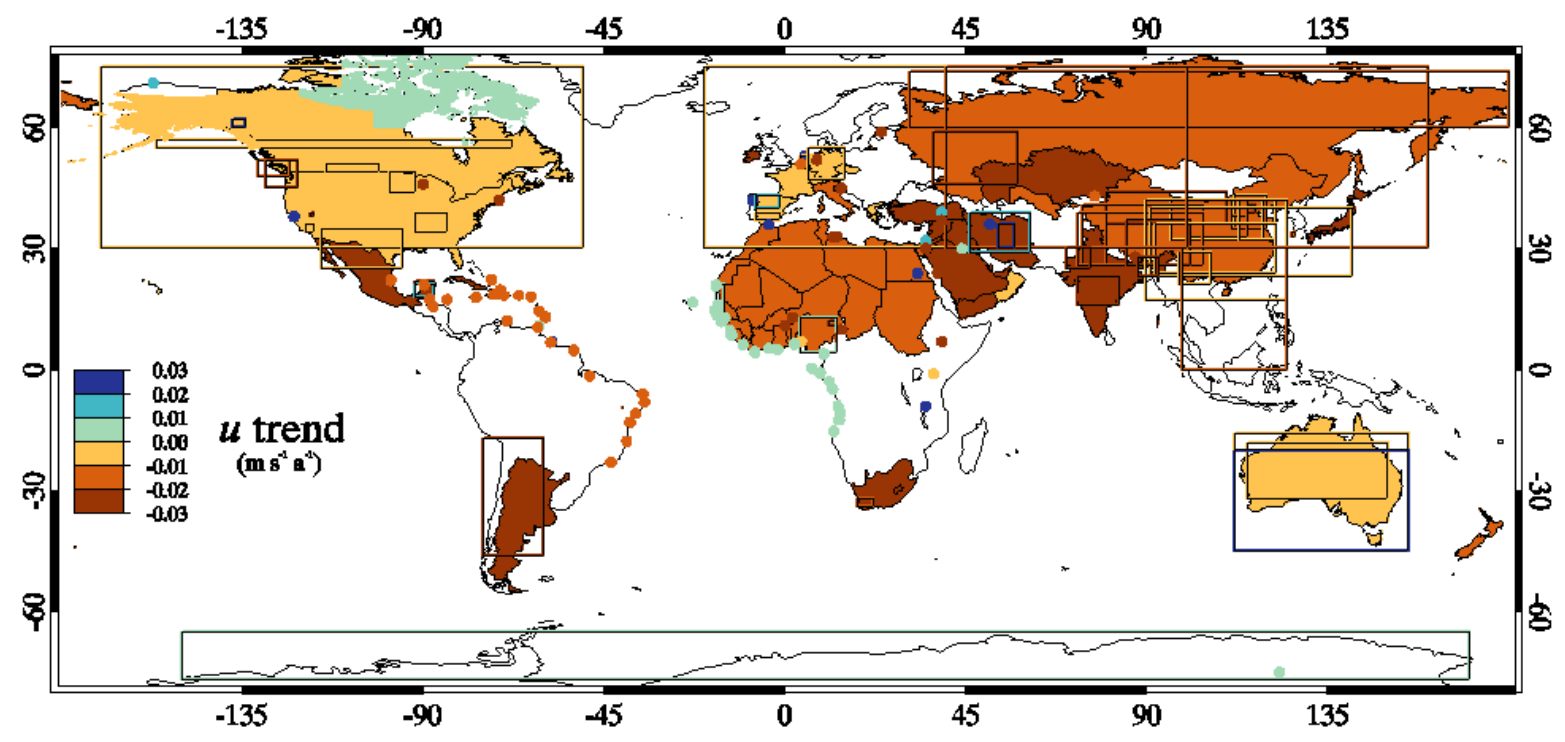

Figure 4: Trends in observed surface wind speeds (in $\mathrm{m} / \mathrm{s}$ per annum). Reprinted from Ref. 26 with permission from Elsevier.

\section{A View from Model Data}

More recently, researchers have turned to numerical models to produce more consistent datasets in order to analyse long term geographical trends in wind speeds. One particular form of numerical model output that has been used for this purpose is referred to as reanalysis. Reanalysis datasets are produced by assimilating a large number of different meteorological datasets including: satellite measurements, ship-borne and buoy observations, land-based surface observations, upper air measurements and remote sensing observations. The data are input to a Global Circulation Model (GCM) which is essentially a numerical weather prediction model which can be used to produce 'hindcast' values of a range of meteorological variables on a regular grid at discrete time intervals. Such output data are effectively homogenised and avoid some of the problems associated with local effects which are seen at specific surface stations. For that reason, reanalysis data are suitable for constructing long term regional climatologies. Two notable examples include the NCEP/NCAR ${ }^{37}$ and the ERA- $40^{38}$ reanalysis datasets. These and other similar datasets have been used to study long term wind speed trends in several parts of the world.

\section{Europe}

An analysis of $850 \mathrm{mb}$ winds from NCEP/NCAR reanalysis data ${ }^{39}$ suggests a general increase in wind speeds over the Baltic region with the majority of the increase during the winter. Over higher altitudes in Switzerland there is evidence for reducing wind speeds with the decline observed to be more rapid than at lower altitudes ${ }^{40}$. A note of caution is sounded in using reanalysis datasets to infer wind speed statistics at sites. It has been seen that when comparing reanalysis wind speed distributions with observations in Hungary ${ }^{41}$ that there are differences in the shape of these distributions and care needs to be taken when rescaling $10 \mathrm{~m}$ values to typical wind turbine hub height. 
The Modern-Era Retrospective Analysis for Research and Applications (MERRA) reanalysis dataset ${ }^{42}$ was studied to consider spatial variation in wind speed and potential wind power trends across the $\mathrm{USA}^{43}$. The wind power density (WPD) and variability or Robust Coefficient of Variation (RCoV) were determined showing large variation across the country. The RCoV is defined as:

$$
R \operatorname{CoV}=\frac{\text { median (absolute deviation about the median) }}{\text { median }}
$$

The RCoV gives a better measure of variability when a distribution is non-gaussian distributed. Figure 5 shows the geographical variation in RCoV across the USA including off the east and west coasts. There are clear differences in trends between the eastern and western sides of the USA as well as in the offshore regions which will have implications for wind energy variability.

A comparison was made between wind speed trends from two observational datasets, four reanalysis datasets and two regional climate models (RCMs) in the USA ${ }^{44}$. This showed conflicting results with the observed data indicating a significant long-term decline in wind speed over time. The model data results differ with one reanalysis dataset and one of the RCMs indicating a decline, but the other models showing an increase.

The North American Regional Climate Change Assessment Program (NARCCAP) uses a combination of a GCM and an RCM to produce high resolution datasets on a regular grid $^{45}$. This was used to study trends in wind speeds over the western High Plains for the period 1971-2000 ${ }^{46}$. A significant decline in wind speeds was seen in all seasons (up to 20\%) with exception of the autumn (fall) season where an increase of up to $10 \%$ was seen. This study extrapolated wind speeds from $10 \mathrm{~m}$ to $80 \mathrm{~m}$ above the ground using the 1/7 power law. In another study, the North American Regional Reanalysis Dataset $(\mathrm{NARR})^{47}$ was used to estimate $80 \mathrm{~m}$ wind speeds by interpolating between the closest model levels ${ }^{48}$. By contrast, this study found increasing wind speeds for the period 1979-2009. This was put down to the strengthening of low level jets which are not as apparent at lower altitudes. The findings of this study were consistent with those of an earlier study looking at changes in wind speeds over the Great Lakes region of the USA ${ }^{49}$. 


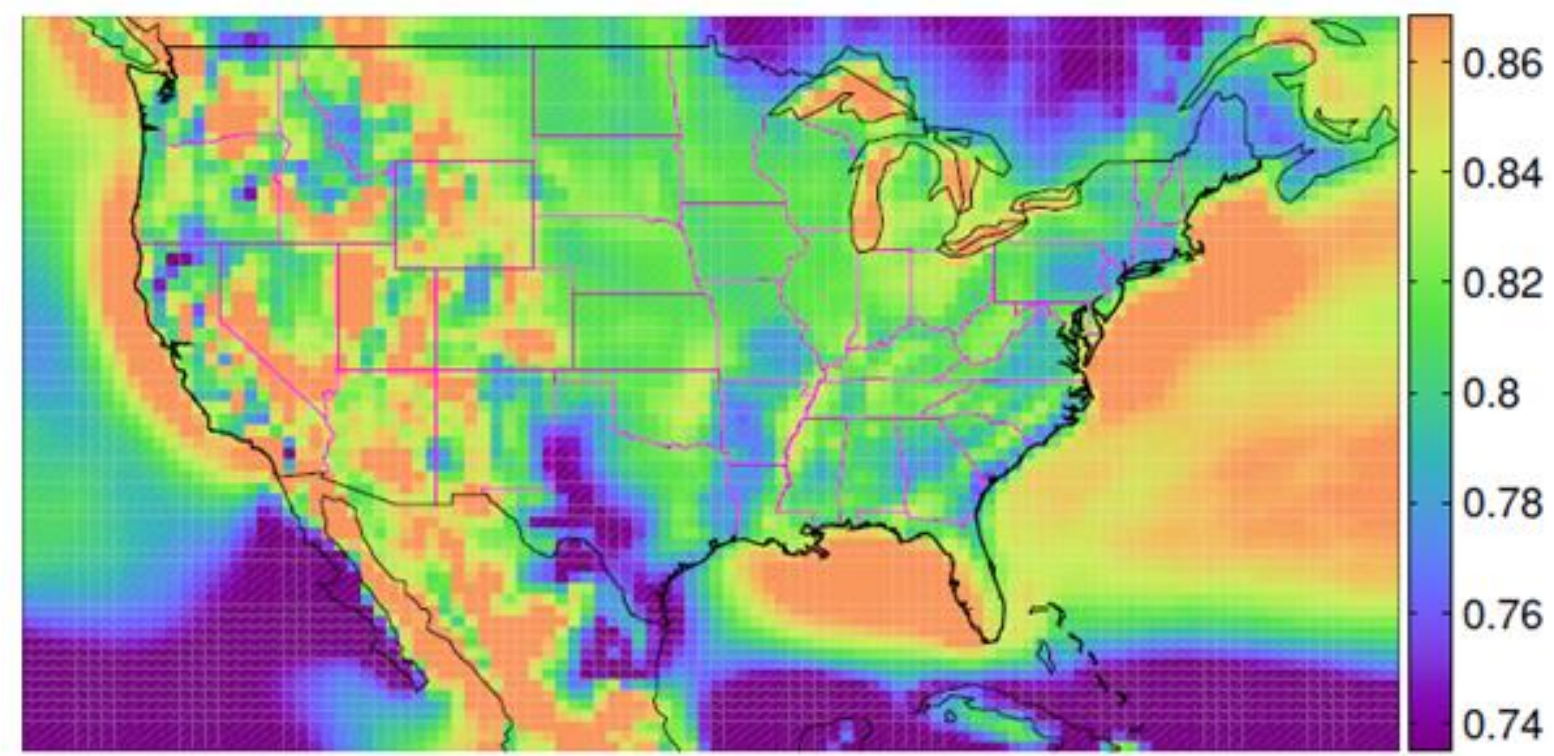

Figure 5: Robust Coefficient of Variability (RCoV) across the USA. Reprinted from Ref. 43 under the Creative Commons Attribution 3.0 License.

\section{Future Trends}

Atmosphere-Ocean General Circulation Models (AOGCMs) can be used to project the climate into the future. By including future carbon dioxide emissions in a model run according to various emissions scenarios as defined by the Intergovernmental Panel on Climate Change (IPCC $)^{50}$, changes in the world climate can be determined. This has been done using a number of well-known AOGCMs such as HadCM3, ECHAM5 and PCM. The IPCC issues periodic Assessment Reports (ARs) including details of the results of these models, e.g. Ref. 51. Downscaling of the AOGCM data using RCMs allows regional future climatologies to be assessed including wind speeds. The confidence intervals for the projections of future global temperature rise are by all standards quite large. In the case of wind speed, projected changes are even more uncertain reflecting the difficulties that such models have in tracking the precise paths of weather systems and how they might change under future climate change scenarios.

Once again, much of the research in this area has focussed on Europe and the USA, though there has been some work in other regions. A recent review has looked at projections for wind speed changes globally and their impact on wind energy $y^{52}$. This showed that wind energy density in Europe is predicted to increase in the north and decrease in the south-east. It was concluded that little work had been done to assess potential changes in inter-annual variability, but that given storm tracks were likely to change, it was likely that variability would change also. The review concluded that mean changes in annual wind speed and variability across the USA and Europe were unlikely to be greater than the present observed inter-annual variability. This work highlights the problems in assessing projected changes in wind speeds where any climate change signal is difficult to detect within the 'noise' of year-to-year variability in mean wind speeds. 


\section{Europe}

In a preliminary assessment of changes in wind speeds across the UK by the $2080 \mathrm{~s}^{53}$, it was seen using data from the UK Climate Impacts Programme that a slight increase of around $0.5 \%$ was predicted nationally. This result disguised significant trends in seasonal wind speeds and potential wind energy production with winter production rising by up to $15 \%$ in the south and falling in the north, whereas summer production would tend to fall by up to $10 \%$ although some areas would experience more severe reductions. When using the $\mathrm{ECHAM} 4^{54}$ and $\mathrm{ECHAM} 5^{55} \mathrm{GCM}$ models to drive the RCA3 $\mathrm{RCM}^{56}$, there was evidence for a reduction in wind speeds over central Scotland and an increase over Eastern England by the mid-21 ${ }^{\text {st }}$ century. Over Ireland, a general slight increase was projected with the greatest change in the north and least in the south. A greater wind energy density was observed in the winter with less in the summer.

A number of AOGCM predictions have been downscaled to assess likely changes in the wind climate over France by the end of the $21^{\text {st }}$ century ${ }^{57,58}$. This showed a potential increase in wind resource during the winter and decrease during the summer in the north of the country and a year-round decrease in the south, though once again, the climate signal was said to be small compared with the inter-annual variability.

USA

A comparison between the CGCM1 and HadCM2, suggested reductions in wind speeds in the windiest mid-west states of between 10-15\% for the former model and little change according to the latter by the end of the $21^{\text {st }}$ century ${ }^{59}$. A projection of the climate in several regions of California by the mid- $21^{\text {st }}$ century using data from NARCCAP showed only slight changes in wind speeds and conflicting regional results ${ }^{60}$. Statistically downscaled scenarios using four GCMs suggested that under a warmer climate, the wind power resource in the Northwest USA could decrease by up to $40 \%$ in the spring and summer months ${ }^{61}$. In winter months, the results were less consistent, with most sites indicating less of a reduction in wind power resource. However, a large degree of variability was seen between the models making it hard to have significant confidence in the predictions. Other work has suggested that different model combinations produce conflicting results. A comparison of several AOGCM/RCM combinations looking at changes in wind speeds by $2055^{62}$ suggested that the variation between different combinations was larger than any possible climate change signal shown by a single combination.

\section{Other Parts of the World}

An analysis of the potential wind speed changes in some other parts of the world has projected somewhat larger changes. In the case of Brazil, an analysis of HadCM3 projections up to 2100 using $A 2$ and $B 2$ scenarios ${ }^{63}$ showed a $>20 \%$ increase in wind speeds over much of the country, particularly the north central region and the east coast. A potential $>20 \%$ reduction was projected for the far west region of the country. An illustration of these regional changes in wind speed are shown in Figure 6.

Over the Caribbean, a combination of a GCM and a mesoscale model suggested a slight increase in wind speeds, with stronger easterlies ${ }^{64}$. An average increase of $0.11 \mathrm{~m} / \mathrm{s}$ over the 21 st century was estimated. 

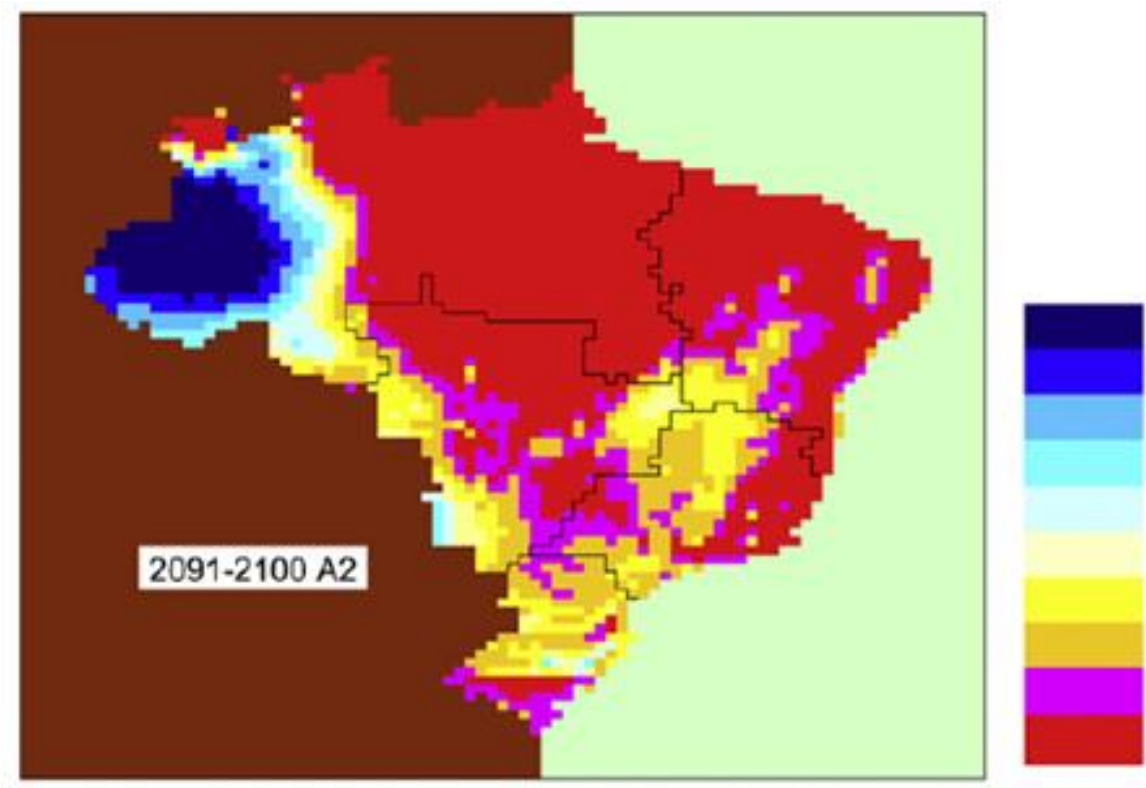

Variation $<-20 \%$
Variation $>-20 ;<-15 \%$
Variation $>-15 ;<-10 \%$
Variation $>-10 ;<-5 \%$
Variation $>-5 ;<0 \%$
Variation $>0 ;<5 \%$
Variation $>5 ;<10 \%$
Variation $>10 ;<15 \%$
Variation $>15 ;<20 \%$
Variation $>20 \%$

Figure 6: Projected changes in wind speed across Brazil by 2091-2100 under the IPCC A2 emissions scenario relative to the 1961-1990 baseline. Reprinted from Ref. 63 with permission from Elsevier.

\section{The Impact of Variability on Wind Power}

There has been much research over the last 30 years on the impact that wind power will have on an electricity network. By its very nature, wind power is a variable source of generation whose availability is heavily dependent on the strength of the wind. When wind power represents a small fraction of the overall generation mix in an electricity system, this presents little problem, since the existing conventional generation plant has sufficient flexibility to cope with this variability. Indeed, all large interconnected power systems have developed to meet a fluctuating and not wholly predictable consumer demand. Once wind power starts to generate an appreciable amount of the total energy in an electricity network, of the order of $20 \%{ }^{65}$, there starts to be an impact on the way that system operates. There are generally three main impacts on the system: 1 ) there is a requirement for extra flexible reserve generation (called spinning reserve) to meet unforeseen changes in generation (or demand); 2) flexible power plant will see increased cycling due to the impact of greater variability and 3 ) there will be periods when not all wind generation can be used and wind farm output may need to be curtailed. All of these have an adverse economic impact on the operation of a power system if not properly managed. The costs associated with this impact have been estimated as 1.0-3.9 $€ / \mathrm{MWh}$ when wind power generates $10 \%$ of energy demand to $2.0-$ 4.6 $€ / \mathrm{MWh}$ when this increases to $30 \%{ }^{66-71}$.

Clearly, the spatial and temporal variability of the wind will influence the level of economic impact: if wind speeds are relatively constant and predictable the impact will be small; if they are highly variable and unpredictable the impact may be large. A number of studies have looked at the impact of temporal and spatial variability on the potential economic benefits of large penetrations of wind power. 
The rate of change or ramp rate for wind power is important when looking at how quickly reserve capacity may need to increase or decrease its output. Data derived from 1500 turbines in Germany totalling around $350 \mathrm{MW}$ showed that the mean hourly ramp rate was $+/-1 \%$ of the installed capacity $^{72}$. The maximum changes observed in one hour were a $23 \%$ decrease and a $14 \%$ increase. Over a four hour period, the maximum changes were found to be larger, at $+/-50 \%$. Similar results were obtained from a study of six wind farms in Northern Ireland. Over half-hourly intervals, the magnitude of wind power fluctuation was shown to be mostly within the $0-10 \%$ range and only rarely exceeding $20 \%$.

Due to the finite size of weather systems, a way to help manage the integration of wind power into a network is to ensure that wind farms are geographically spread ${ }^{73}$. This reduces the correlation in output between different wind farms and thus helps to smooth output. Careful planning of site selection to favour combinations of sites with a low or negative correlation could be beneficial ${ }^{74}$. A study of wind energy in Greece concluded that aggregation over a wide area improves the capacity factor $^{75}$. A UK study concluded that by spreading out $2.7 \mathrm{GW}$ of wind power over four sites, a $36 \%$ reduction in variability was possible compared to a single site ${ }^{76}$. An analysis of 20 sites in Texas, USA $^{77}$ found that significant reductions in variability over a $24 \mathrm{~h}$ period were achievable by aggregating the output of several wind farms with an $87 \%$ reduction compared to the variability of a single wind plant obtained by interconnecting four wind plants. Interconnecting a further 16 wind plants produced only an additional $8 \%$ reduction. A large degree of inter-annual variability was observed over a 36 year period, though less than for hydroelectric power; this was also confirmed by a study in Portugal ${ }^{78}$. A significant finding was that the correlation coefficient between pairs of sites decayed significantly faster than was observed across Europe though a large degree of scatter in both the Texas and European data was noted. This is shown in Figure 7 with a best fit exponential decay curve fitted to the Texas data in red compared to the European data ${ }^{79}$ in green. Additionally, it was found, that by combining the power output of wind farm sites, the relative step changes in power seen at individual sites reducing substantially ${ }^{77}$. By adding more distant wind farms to the 'portfolio' it was found that the maximum step change in power relative to the maximum power produced by the portfolio reached an asymptote of $15-30 \%$ for step changes of an hour or less.

A further analysis looking at regional interconnection across the $U \mathrm{~S}^{80}$ showed that variability benefits diminish but there is a decrease in the likelihood of sudden step changes in aggregate wind power generation. A study of potential offshore wind power off the East Coast of the USA using data from 11 coastal meteorological sites ${ }^{81}$ concluded that the combined output of offshore wind farms interconnected over a length of $2500 \mathrm{~km}$ rarely reached low or full output and changed more slowly than for individual sites. Over a five-year period, the combined output was never zero.

Variability has been shown to be more dependent on region size than number of wind farms, once the output of more than $\sim 50$ wind farms is aggregrated ${ }^{82}$. This allows the so-scaled 'upscaling' effect whereby the effect of increased capacity of wind power across a country can be accurately represented by scaling up the capacity of a number of wind farms provided they are spaced sufficiently.

It has been argued that by scaling up the level of interconnection across Europe it would be possible to maintain a more stable and continuous supply of wind power. ERA-40 data were analysed over a period of 44 years across Europe to study how an interconnected network could maintain a target 
level of wind power generation across the continent ${ }^{83}$. This study found it is difficult to maintain even a modest target level for a long period. This is due to the large degree of spatial correlation and low autocorrelation as shown graphically in Figure 8. These plots show that the typical correlation length is between $400-600 \mathrm{~km}$ and the autocorrelation time typically $<2$ days. Although interconnection could limit fluctuations in wind power across the continent, there are limitations and the effect of European-wide low wind speed events cannot be eliminated.

Inter-annual variability of wind energy has significant implications for the cash flow of a wind farm operator. The year on year variation in wind speeds averaged over a number of sites relative to the long term mean can be evaluated using a so-called wind index. For the Nordic countries and the Baltic States ${ }^{84}$, it was shown the standard deviations of the wind indices over the period 1960-1981, normalised to the period 1990-2001, ranged from $8 \%$ to $12 \%$ depending on country and reanalysis dataset. For the $\mathrm{UK}^{29}$, the standard deviation of a wind index calculated over 51 years averaged over seven stations was found to be $4 \%$ based on surface observations; for a larger sample of 60 stations over a 25 -year period, the standard deviation was found to be $5 \%$. For meteorological stations in Scotland ${ }^{30}$ over a period of 43 years, the inter-annual change in hypothetical capacity factor was studied, where the capacity factor is defined as the average power output of a wind farm divided by its rated power output over the long term. It was found that the average volatility in wind power output for 10 sites, estimated as the difference between the capacity factor in one year compared to that from the previous year and then normalised by the current capacity factor, was found to be $15 \%$.

Another possibility to reduce the effect of wind power variability is to combine it with other sources of renewable energy generation. The wind and wave power resource around the coast of Ireland was studied ${ }^{85}$ and it was found that west and south coasts of Ireland experience wave conditions which are generated by distant winds far out in the Atlantic which are little correlated to the wind conditions close to the coast. This provides a good opportunity for co-located wind and wave power generation whereby combined power output is smoothed. A similar conclusion was drawn for the Californian coast of the USA ${ }^{86}$, where aggregated power from a co-located wind and wave farms was found to achieve reductions in variability equivalent to aggregating power from two offshore wind farms approximately $500 \mathrm{~km}$ apart or two wave farms approximately $800 \mathrm{~km}$ apart. A study in Denmark looked at optimal combinations for wind, wave and photovoltaic (PV) power ${ }^{87}$ which noted that though the three generation sources were to some extent complementary, this was not a complete solution in terms of integrating variable renewable energy generation. 


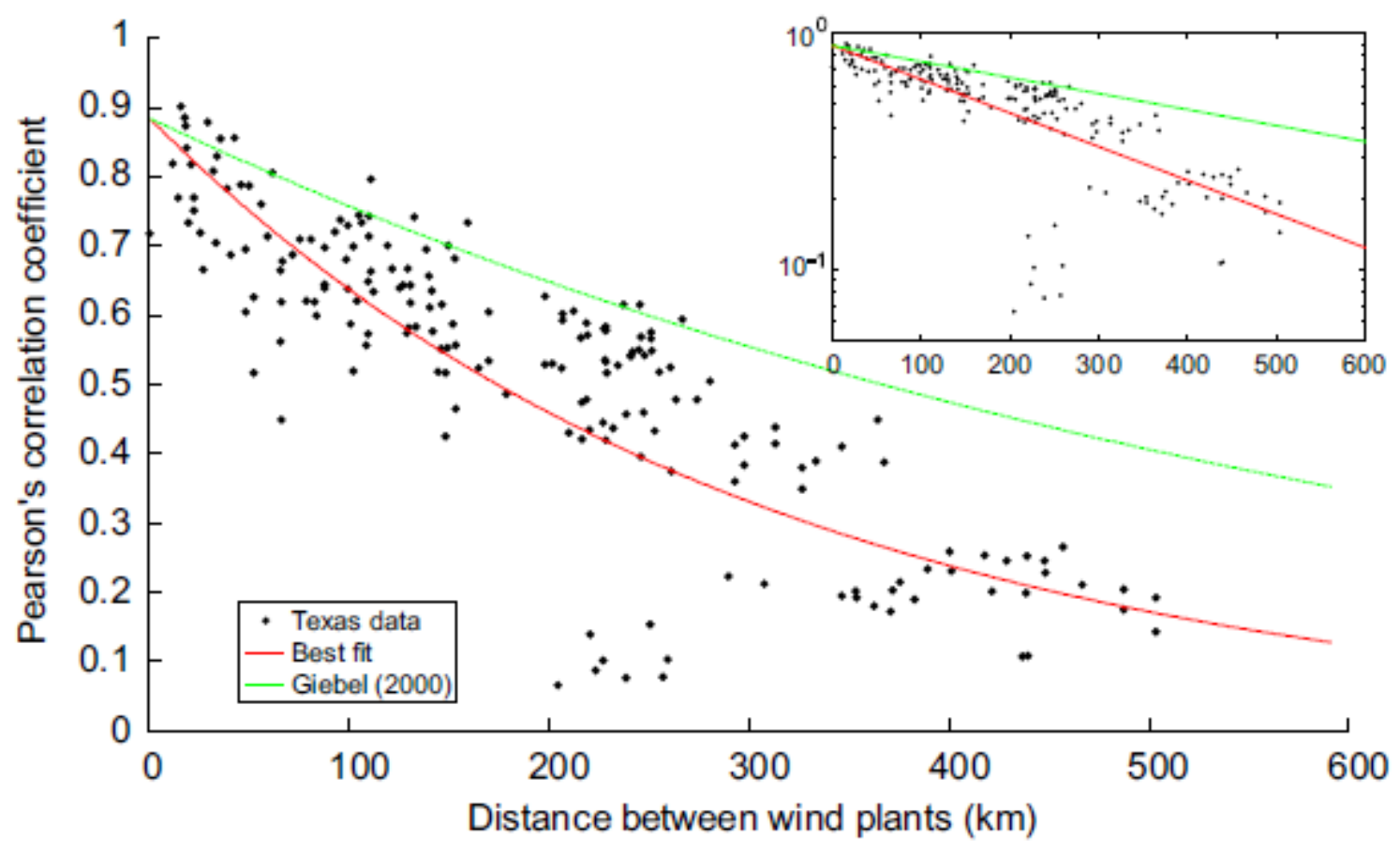

Figure 7: Correlations $(\rho)$ between pairs of wind farm sites in Texas compared with sites in Europe. Best fit exponential decay curves are shown for the two regions. The decay curves have the form $\rho \propto \exp (-$ Distance $/ D)$ where $D$ is the characteristic decay distance $(305 \mathrm{~km}$ for Texas and $641 \mathrm{~km}$ for Europe). Reprinted from Ref. 77 with permission from Elsevier.
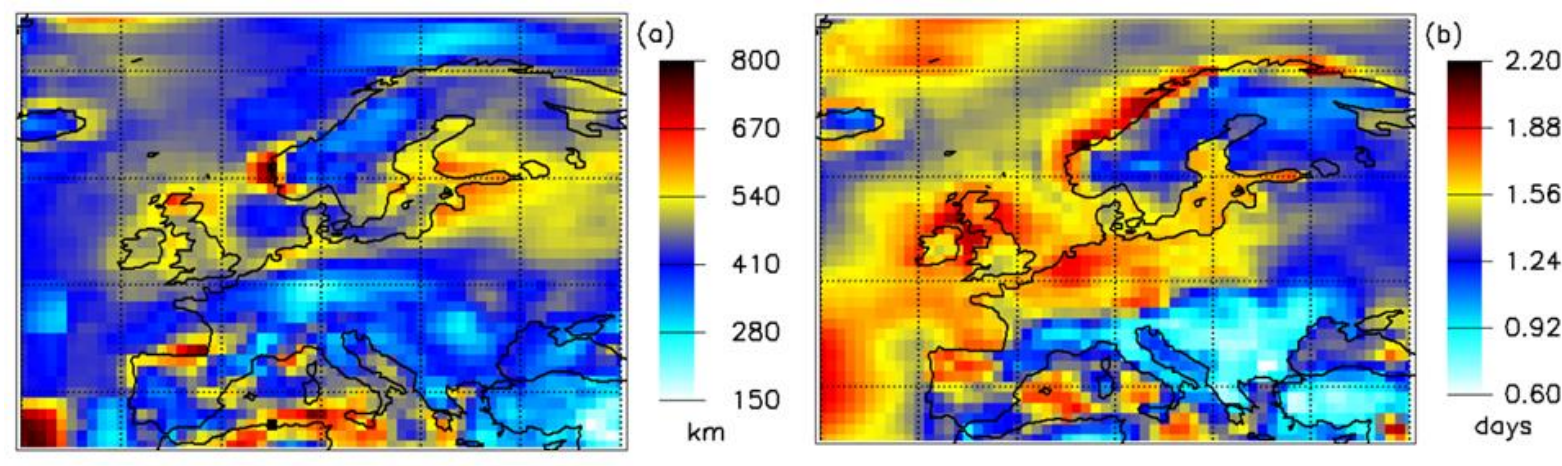

Figure 8: (a) Average correlation length and (b) autocorrelation time inferred from ERA-40 data over a 44 year period. Reprinted from Ref. 83 under the Creative Commons Attribution 3.0 License.

\section{Conclusion}

Understanding and managing the variability of the wind will be increasingly important as a larger fraction of electricity is generated by wind farms. The use of the Weibull distribution in estimating expected energy yields is well-established and though there are some sites where it does not fit the observed wind distributions, hybrid bi-modal distributions have been shown to perform well. Observations of long term wind speeds seem to show that globally wind speeds are diminishing though this conclusion should be viewed with caution due to inhomogeneities in surface measurements. The conclusions to be drawn from model output such as reanalysis data are less 
clear, though there is evidence from these for declining wind speeds in some regions. Climate change predictions for changes in wind speed are even more uncertain and most studies in this area have concluded that any possible climate change related signals are smaller than the observed interannual variability. Much research has been done to look at how dispersion of wind farms and increased interconnection could be used to manage variability. It has been concluded that this will help reduce variability, but that there are limits on how well this can help the integration of large amounts of wind power into electricity networks due to the relatively large spatial correlation of wind speeds. Combinations of different renewable generation technologies can play a role, but again, this is not the entire answer.

Looking to the future, more work needs to be done to understand potential long term changes in global wind speeds including mean wind speeds and extremes. In particular, modelling uncertainties need to be reduced if there is to be more confidence in expected future wind speed changes.

Modelling of the integration of wind power into networks will need to consider other options to reduce the variable impact of wind power including the role that can be played by combinations of different renewable generation technologies, demand side management, electric vehicles and energy storage along with smarter control of wind farms.

\section{References}

1. http://gwec.net/wp-content/uploads/2012/06/Annual report 2011 lowres.pdf . Last accessed 28/3/13.

2. Van der Hoven I. Power spectrum of horizontal wind speed in the frequency range from 0.0007 to 900 cycles per hour. Journal of Meteorology 1957, 14: 160-164.

3. Smedman-Högström A-S and Högström U. Spectral gap in surface-layer measurements. Journal of the Atmospheric Sciences 1975, 32: 340-350.

4. Lovejoy S, Schertzer D and Stanway JD. Direct evidence of multifractal atmospheric cascades from planetary scales down to $1 \mathrm{~km}$. Physical Review Letters 2001, 86: 5200-5203.

5. Böttcher F, Barth S and Peinke J. Small and large scale fluctuations in atmospheric wind speeds. Stochastic Environmental Research and Risk Assessment 2007, 21: 299-308.

6. Laubrich T and Kantz, H. Statistical analysis and stochastic modelling of boundary layer wind speed. European Physical Journal - Special Topics 2009, 174: 197-206.

7. Pryor SC, Barthelmie RJ, Schoof JT. The impact of non-stationarities in the climate system on the definition of 'a normal wind year': A case study from the Baltic. International Journal of Climatology 2005, 25: 735-752.

8. Burton T, Sharpe D, Jenkins $\mathrm{N}$ and Bossanyi E. Wind Energy Handbook. John Wiley and Sons, Ltd, Chichester, UK, 2001, ISBN 0-471-48997-2.

9. Garcia A, Torresa JL, Prietoa E and de Francisco A. Fitting wind speed distributions: a case study. Solar Energy 1998, 62: 139-144. 
10. Rehman S, Halawani TO and Husain T. Weibull parameters for wind speed distribution in Saudi Arabia. Solar Energy 1994, 53: 473-479.

11. Celik AN. Energy output estimation for small-scale wind power generators using Weibullrepresentative wind data. Journal of Wind Engineering and Industrial Aerodynamics 2003, 91: 693-707.

12. He Y, Monahan AH, Jones CG, Dai A, Biner S, Caya D and Winger K. Probability distributions of land surface wind speeds over North America. J. Geophys. Res. 2010, 115: D04103.

13. Monahan AH and He Y. The probability distribution of land surface wind speeds. Journal of Climate 2011, 24: 3892-3909.

14. Monahan AH. The probability distribution of sea surface wind speeds. Part I: Theory and SeaWinds observations. Journal of Climate 2006, 19: 497-520.

15. Monahan AH. The probability distribution of sea surface wind speeds. Part II: Dataset intercomparison and seasonal variability. Journal of Climate 2006, 19: 521-534.

16. Bauer E. Characteristic frequency distributions of remotely sensed in situ and modelled wind speeds. International Journal of Climatology 1996, 16: 1087-1102.

17. Kozai K, Ohsawa T, Takahashi R and Takeyama Y. Evaluation method for offshore wind energy resources using scatterometer and Weibull parameters. Journal of Energy and Power Engineering 2012, 6: 1772-1778.

18. Karagali I, Peña A, Badger M and Hasager CB. Wind characteristics in the North and Baltic Seas from the QuikSCAT satellite. Wind Energy 2012, in press, DOI: 10.1002/we.1565.

19. Coelingh JP, van Wijk AJM and Holtslag AAM. Analysis of wind speed observations over the North Sea. Journal of Wind Engineering and Industrial Aerodynamics 1996, 61: 51-69.

20. Jamil M, Parsa S and Majidi M. Wind power statistics and an evaluation of wind energy density. Renewable Energy 1995, 6: 623-628.

21. Carta JA, Ramírez P and Velázquez S. A review of wind speed probability distributions used in wind energy analysis: Case studies in the Canary Islands. Renewable and Sustainable Energy Reviews 2009, 13: 933-955.

22. Deaves DM and Lines IG. On the fitting of low mean windspeed data to the Weibull distribution. Journal of Wind Engineering and Industrial Aerodynamics 1997, 66: 169-178.

23. Carta JA and Ramírez P. Analysis of two-component mixture Weibull statistics for estimation of wind speed distributions. Renewable Energy 2007, 32:2007: 518-531.

24. Jaramillo OA and Borja MA. Wind speed analysis in La Ventosa, Mexico: a bimodal probability distribution case. Renewable Energy 2004, 29: 1613-1630.

25. Carta JA and Ramirez P. Use of finite mixture distribution models in the analysis of wind energy in the Canarian Archipelago. Energy Conversion and Management 2007, 48: 281-291. 
26. McVicar TR, Roderick ML, Donohue RJ, Li LT, Van Niel TG, Thomas A, Grieser J, Jhajharia D, Himri Y, Mahowald NM, Mescherskaya AV, Kruger AC, Rehman S, Dinpashoh Y. Global review and synthesis of trends in observed terrestrial near-surface: implications for evaporation . Journal of Hydrology 2012, 416-417: 182-205.

27. Greene S, Morrissey M and Johnson SE. Wind climatology, climate change, and wind energy. Geography Compass 2010, 4/11: 1592-1605.

28. Vautard R, Cattiaux J, Yiou P, Thépaut J-N and Ciais P. Northern Hemisphere atmospheric stilling partly attributed to an increase in surface roughness. Nature Geoscience 2010, 3: 756-761.

29. Watson S J and Kritharas P. Long Term Wind Speed Variability in the UK. Proceedings of European Wind Energy Association Annual Event 2012, Copenhagen, 16th - 19th April 2012.

30. Früh W-G. Long-term wind resource and uncertainty estimation using wind records from Scotland as example. Renewable Energy 2013, 50: 1014-1026.

31. Bakker AMR and van den Hurk BJJM. Estimation of persistence and trends in geostrophic wind speed for the assessment of wind energy yields in Northwest Europe. Climate Dynamics 2012, 39: 767-782.

32. Bärring $L$ and Fortuniak K. Multi-indices analysis of southern Scandinavian storminess 1780-2005 and links to interdecadal variations in the NW Europe-North Sea region. International Journal of Climatology 2009, 29: 373-384.

33. Wang XL, Zwiers FW, Swail VR and Feng Y. Trends and variability of storminess in the Northeast Atlantic region, 1874-2007. Climate Dynamics 2009, 33: 1179-1195.

34. Palutikof JP, Guo X and Halliday JA. Climate variability and the UK wind resource. Journal of Wind Engineering and Industrial Aerodynamics 1992, 39: 243-249.

35. Brayshaw DJ, Troccoli A, Fordham R and Methven J. The impact of large scale atmospheric circulation patterns on wind power generation and its potential predictability: A case study over the UK. Renewable Energy 2011, 36: 2087-2096.

36. Atkinson N, Harman K, Lynn M, Schwarz A and Tindal A. Long-term wind speed trends in northwestern Europe. Proceedings of the BWEA28 conference, Glasgow, October 2006 [Internet]. Available from http://www.glgarradhassan.com/assets/downloads/Long_term_wind_speed_trends_in_northwestern_Europe .pdf, last accessed 22nd February 2013.

37. Kalney E et al. The NCEP/NCAR 40-year reanalysis project. Bulletin of the American Meteorological Society 1997, 77: 437-471.

38. Uppala SM et al. ERA-40 re-analysis. Quarterly Journal of the Royal Meteorological Society 2005, 131: 2961-3012.

39. Pryor SC and Barthelmie RJ. Long-term trends in near-surface flow over the Baltic. International Journal of Climatology 2003, 23: 271-289. 
40. McVicar TR, Van Niel TG, Roderick ML, Li LT, Mo XG, Zimmerman NE and Schmatz DR. Observational evidence from two mountainous regions that near surface wind speeds are declining more rapidly at higher elevations than lower elevations: 1960-2006. Geophysical Research Letters 2010, 37: L06402.1-L06402.6.

41. Kiss $P$, Varga $L$ and Jánosi IM. Comparison of wind power estimates from the ECMWF reanalyses with direct turbine measurements. Journal of Renewable and Sustainable Energy 2009, 1: 033105 (11pp).

42. Rienecker MM et al. MERRA - NASA's Modern-Era Retrospective Analysis for Research Applications. Journal of Climate 2011, 24, 3624-3648.

43. Gunturu UB and Schlosser CA. Characterization of wind power resource in the United States. Atmospheric Chemistry and Physics 2012, 12: 9687-9702.

44. Pryor SC, Barthelmie RJ, Young DT, Takle ES, Arritt RW, Flory D, Gutowski Jr. WJ, Nunes A and Roads J. Wind speed trends over the contiguous United States. Journal of Geophysical Research 2009, 114: D14105.

45. Mearns LO et al. A regional climate change assessment program for North America. EOS 2009, 90: 311-312.

46. Greene SJ, Chatelain M, Morrissey M and Stadler S. Estimated changes in wind speed and wind power density over the western High Plains, 1971-2000. Theoretical and Applied Climatology 2012, 109:507-518.

47. Mesinger F, et al. North American reanalysis. Bulletin of the American Meteorological Society 2006, 87: 343-360.

48. Holt E and Wang J. Trends in wind speed at wind turbine height of $80 \mathrm{~m}$ over the contiguous United States using the North American Regional Reanalysis (NARR). Journal of Applied Meteorology and Climatology 2012, 51: 2188-2202.

49. Li X, Zhong S, Bian X and Heilman WE. Climate and climate variability of the wind power resources in the Great Lakes region of the United States. Journal of Geophysical Research 2010, 115: D18107.

50. IPCC Special Report on Emissions Scenarios, 2000. Available at: http://www.grida.no/publications/other/ipcc sr/?src=http://www.grida.no/climate/ipcc/, last accessed 26/3/13.

51. Solomon S. Qin D, Manning M, Chen Z, Marquis M, Averyt KB, Tignor M and Miller HL (eds.). Contribution of Working Group I to the Fourth Assessment Report of the Intergovernmental Panel on Climate Change, 2007. Cambridge University Press, Cambridge, United Kingdom and New York, NY, USA. Available at:

http://www.ipcc.ch/publications and data/ar4/wg1/en/contents.html, last accessed 26/3/13.

52. Pryor SC and Barthelmie RJ. Climate change impacts on wind energy: A review. Renewable and Sustainable Energy Reviews 2010, 14: 430-437. 
53. Harrison GP, Cradden LC and Chick JP. Preliminary assessment of climate change impacts on the UK onshore wind energy resource. Energy Sources Part A - Recovery Utilization and Environmental Effects 2008, 30: 1286-1299.

54. Roeckner E, Arpe K, Bengsson L, Christoph M, Claussen M, Duemenil L, Esch M, Giorgetta M, Schlese U, Schulzweida U, Giorgetta M, Schlese U. The atmospheric general circulation model ECHAM-4: model description and simulation of present-day-climate. Report No. 218, Max Planck Institute for Meteorology, Hamburg, Germany, 1996.

55. Roeckner E, Bauml G, Bonaventura L, Brokopf R, Esch M, Giorgetta M, Hagemannn S, Kirchner I, Kornblueh L, Manzini E, Rhodin A, Schlese U, Schulzweida U, Tompkins A. The atmospheric general circulation model ECHAM5 part I: model description. Report No. 349, Max Planck Institute for Meteorology, Hamburg, Germany, 2003.

56. Nolan P, Lynch P, McGrath R, Semmler T and Wang S. Simulating climate change and its effects on the wind energy resource of Ireland. Wind Energy 2012, 15: 593-608.

57. Najac J, Boé J and Terray L. A multi-model ensemble approach for assessment of climate change impact on surface winds in France. Climate Dynamics 2009, 32: 615-634.

58. Najac J, Lac C and Terray L. Impact of climate change on surface winds in France using a statistical-dynamical downscaling method with mesoscale modelling. International Journal of Climatology 2011, 31: 415-430.

59. Breslow PB and Sailor DJ. Vulnerability of wind power resources to climate change in the continental United States. Renewable Energy 2002, 27: 585-598.

60. Rasmussen DJ, Holloway T and Nemet GF. Opportunities and challenges in assessing climate change impacts on wind energy-a critical comparison of wind speed projections in California. Environmental Research Letters 2011, 6: 024008 (9pp).

61. Sailor DJ, Smith M, Hart M. Climate change implications for wind power resources in the Northwest United States. Renewable Energy 2008, 33: 2393-2406.

62. Pryor SC and Barthelmie RJ. Assessing climate change impacts on the near-term stability of the wind energy resource over the United States. Proceedings of the National Academy of Sciences of the USA 2011, 108: 8167-8171.

63. Pereira de Lucena AF, Szklo AS, Schaeffer R and Dutra RM. The vulnerability of wind power to climate change in Brazil. Renewable Energy 2010, 35: 904-912.

64. Angeles ME, González JE, Erickson DJ and Hernández JL. The impacts of climate changes on the renewable energy resources in the Caribbean region. Transactions of the ASME: Journal of Solar Energy Engineering 2010, 132, 031009 (13pp).

65. Grubb M, Butler L and Twomey P. Diversity and security in UK electricity generation: The influence of low-carbon objectives. Energy Policy 2006, 34: 4050-4062. 
66. Angarita-Márquez JL, Hernandez-Aramburo CA and Usaola-Garcia J. Analysis of a wind farm's revenue in the British and Spanish markets. Energy Policy 2007, 35: 5051-5059.

67. Swider DJ, Beurskens L, Davidson S, Twidell J, Pyrko J, Prüggler W, Auer H, Vertin K and Skema R. Conditions and costs for renewables electricity grid connection: Examples in Europe. Renewable Energy 2008, 33: 1832-1842.

68. Dale L, Milborrow D, Slarkc R and Strbac G. Total cost estimates for large scale wind scenarios in UK. Energy Policy 2004, 32: 1945-1956.

69. Holttinen $\mathrm{H}$. Handling of wind power forecast errors in the Nordic power market. Proceedings of Probabilistic Methods Applied to Power Systems 2006, Stockholm, Sweden 11-15 June 2006.

70. Holttinen $\mathrm{H}$ et al. Design and operation of power systems with large amounts of wind power. Final report, IEA WIND Task 25. Phase one 2006-2008. ISBN 978-951-38-7308-0, published by VTT, Technical Research Centre of Finland. Available at: http://www.vtt.fi/inf/pdf/tiedotteet/2009/T2493.pdf last accessed 28/3/13.

71. Chang J, Ummels BC, van Sark WGJHM, den Rooijen HPGM and Kling WL. Economic evaluation of offshore wind power in the liberalized Dutch power market. Wind Energy 2009, 12: 507-523.

72. Hartnell G. Wind on The System-Grid integration of wind power. Renewable Energy World, James and James (Science Publishers) Ltd., March-April 2000.

73. Purvins A, Zubaryeva A, Llorente M, Tzimas E and Mercier A. Challenges and options for a large wind power uptake by the European electricity system. Applied Energy 2011, 88: 1461-1469.

74. Degeilh $Y$ and Singh C. A quantitative approach to wind farm diversification and reliability. Electrical Power and Energy Systems 2011, 33: 303-314.

75. Caralis G, Perivolaris Y, Rados K and Zervos A. On the effect of spatial dispersion of wind power plants on the wind energy capacity credit in Greece. Environmental Research Letters 2008, 3: 015003 (13pp).

76. Drake $B$ and Hubacek K. What to expect from a greater geographic dispersion of wind farms? $-A$ risk portfolio approach. Energy Policy 2007, 35: 3999-4008.

77. Katzenstein W, Fertig E and Apt J. The variability of interconnected wind plants. Energy Policy 2010, 38: 4400-4410.

78. Pestana R. Dealing with limited connections and large installation rates in Portugal. The 2nd Workshop on Best Practice in the Use of Short-term Forecasting, Madrid, Spain, 28 May 2008. Available at: http://powwow.risoe.dk/publ/RPestana (REN)DealingWLimitedConnALargelnstallRatesInPT BestPracticeSTP-2 2008.pdf, last accessed 9/7/13.

79. Giebel G. On the benefits of distributed generation of wind energy in Europe. PhD Dissertation, Carl von Ossietzky University, Oldenburg, 2000, (104pp). Available at: http://www.drgiebel.de/GGiebel DistributedWindEnergyInEurope.pdf , last accessed 28/3/13. 
80. Fertig E, Apt J, Jaramillo P and Katzenstein W. The effect of long-distance interconnection on wind power variability. Environmental Research Letters 2012, 7: 034017 (6pp).

81. Kempton W, Pimenta FM, Veron DE and Colle BA. Electric power from offshore wind via synoptic-scale interconnection. Proceedings of the National Academy of Sciences of the USA 2010, 107: 7240-7245.

82. Hasche B. General statistics of geographically dispersed wind power, Wind Energy 2010, 13 : 773-784.

83. Kiss P and Jánosi IM. Limitations of wind power availability over Europe: a conceptual study. Nonlinear Processes in Geophysics 2008, 15: 803-813.

84. Pryor SC, Barthelmie RJ and Schoof JT. Inter-annual variability of wind indices across Europe. Wind Energy 2006, 9: 27-38.

85. Fusco F, Nolan $\mathrm{G}$ and Ringwood JV. Variability reduction through optimal combination of wind/wave resources - An Irish case study. Energy 2010, 35: 314-325.

86. Stoutenburg ED, Jenkins $\mathrm{N}$ and Jacobson MZ. Power output variations of co-located offshore wind turbines and wave energy converters in California. Renewable Energy 2010, 35: 2781-2791.

87. H. Lund. Large-scale integration of optimal combinations of PV, wind and wave power into the electricity supply. Renewable Energy 2006, 31: 503-515.

\section{Further Reading/Resources}

1. ERA-40 Reanalysis. Available at: http://www.ecmwf.int/products/data/archive/descriptions/e4/, last accessed 28/3/13.

2. NCEP/NCAR Reanalysis. Available at: http://www.esrl.noaa.gov/psd/data/gridded/data.ncep.reanalysis.html, last accessed 28/3/13.

3. NARR (NCEP North American Regional Reanalysis). Available at: http://www.esrl.noaa.gov/psd/data/gridded/data.narr.html, last accessed 28/3/13.

4. NARCCAP (North American Regional Climate Change Assessment Program). Available at: http://www.narccap.ucar.edu/index.html, last accessed 28/3/13.

5. MERRA (Modern Era Retrospective-analysis for Research and Applications). Available at: http://disc.sci.gsfc.nasa.gov/mdisc/, last accessed 28/3/13.

6. UKERC. The Costs and Impacts of Intermittency: An assessment of the evidence on the costs and impacts of intermittent generation on the British electricity network, March 2006.

Available at:

http://www.ukerc.ac.uk/Downloads/PDF/06/0604Intermittency/0604IntermittencyReport.p df, last accessed 28/3/13.

7. IEA (International Energy Agency) Task 25. Design and operation of power systems with large amounts of wind power. Available at: http://ieawind.org/task 25.html, last accessed 10/7/13. 
8. IPCC Working Group III: Mitigation of Climate Change. Special Report on Renewable Energy Sources and Climate Change Mitigation. Available at: http://srren.ipcc-wg3.de/report, last accessed 10/7/13. 